\title{
Sol Gel vs Solid State Synthesis of the Fast Lithium-Ion Conducting Solid State Electrolyte $\mathrm{Li}_{7} \mathrm{La}_{3} \mathrm{Zr}_{2} \mathrm{O}_{12}$ Substituted with Iron
}

\author{
Anja Paulus, $\oplus^{1,2, z}$ Simon Kammler, ${ }^{1,2}$ Sabrina Heuer, ${ }^{1,2}$ Marc C. Paulus, ${ }^{1,3}$ Peter Jakes, ${ }^{1}$ \\ Josef Granwehr, ${ }^{1,3}$ and Rüdiger-A. Eichel ${ }^{1,2}$ \\ ${ }^{I}$ Forschungszentrum Jülich GmbH, Institut für Energie- und Klimaforschung (IEK-9), D-52425 Jülich, Germany \\ ${ }^{2}$ RWTH Aachen University, Institut für Physikalische Chemie (IPC), D-52074 Aachen, Germany \\ ${ }^{3}$ RWTH Aachen University, Institut für Technische und Makromolekulare Chemie (ITMC), D-52074 Aachen, Germany
}

\begin{abstract}
Two calcined products of $\mathrm{Li}_{6.4} \mathrm{Fe}_{0.2} \mathrm{La}_{3} \mathrm{Zr}_{2} \mathrm{O}_{12}$ can be synthesized via the solid state method and the sol gel method. Inhomogeneities of the iron distribution in the powder for the solid state method lead to a combination of cubic and tetragonal structure. By using the sol gel method the homogeneity can significantly been increased resulting in the desired pure phase cubic structured powders in $I \overline{4} 3 d$. By in situ dilatometer measurements the densification process can be comprehended for the first time for garnet type materials. The density can be significantly increased by the usage of the sol gel synthesis compared to the solid state synthesis with short sintering times of $2 \mathrm{~h}$ delivering pure phase pellets for both synthesis methods. Electrical impedance measurements revealed clearly divided semicircles for the bulk and the grain boundary contribution for the solid state synthesis, while the sol gel synthesis showed only one semicircle from the bulk contribution due to a large crystallite size. The total ionic conductivity for the pellet synthesized via the sol gel method is $1.82 \mathrm{mS} / \mathrm{cm}$ at $25^{\circ} \mathrm{C}$ which is the fastest found so far for garnet type or garnet related materials.

(C) The Author(s) 2019. Published by ECS. This is an open access article distributed under the terms of the Creative Commons Attribution 4.0 License (CC BY, http://creativecommons.org/licenses/by/4.0/), which permits unrestricted reuse of the work in any medium, provided the original work is properly cited. [DOI: 10.1149/2.0641903jes]

(cc) BY
\end{abstract}

Manuscript submitted September 12, 2018; revised manuscript received January 7, 2019. Published January 23, 2019. This paper is part of the JES Focus Issue of Selected Papers from IMLB 2018.

The research and development of high-performance fast lithiumion conductors, which are thermally and chemically stable, attracts large interest for the use in all solid state batteries. ${ }^{1,2}$ Integrating solid electrolytes into lithium-ion batteries, enhanced reliability and safety shall be obtained by replacing the conventionally used organic liquid electrolytes that exhibit safety issues including high toxicity, narrow chemical stability window and flammability. ${ }^{3}$ Garnet type electrolytes exhibit a reasonable lithium-ion conductivity with up to $1.62 \mathrm{mS} / \mathrm{cm}$ at room temperature. ${ }^{4,5}$ Furthermore, they have the lowest reduction potential against lithium and present the most thermodynamically stable interphase with lithium among the inorganic ceramic solid state electrolytes. ${ }^{6,7}$ Therefore, they could enable the usage of lithium metal as anode, which may lead to a higher energy density. With respect to the structural features of the lithium-rich $\mathrm{Li}_{7} \mathrm{La}_{3} \mathrm{Zr}_{2} \mathrm{O}_{12}$ composition, two polymorphs have to be distinguished. At room temperature, $\mathrm{Li}_{7} \mathrm{La}_{3} \mathrm{Zr}_{2} \mathrm{O}_{12}$ occurs in the thermodynamically stable tetragonal structure. This structure exhibits about three orders of magnitude lower lithium-ion conductivity than the garnet-type cubic structure in $I a \overline{3} d{ }^{8,9}$ To stabilize the cubic garnet-type structure at room temperature aliovalent substitution can be used. Enhancement of the lithium-ion conductivity can be achieved by substitution on the lithium site with $\mathrm{Al},{ }^{10} \mathrm{Zn},{ }^{11} \mathrm{Ga} .{ }^{12}$ Also iron stabilizes the cubic structure with the difference, that an reduction of symmetry to spacegroup $I \overline{4} 3 d$ is observed caused by the ordering of $\mathrm{Fe}^{3+} \cdot{ }^{13-15}$ For several substituents it was shown that the bulk ionic conductivity is higher than the one of the grain boundary. ${ }^{16-23}$ For iron substitution into the garnet structure this is unknown so far. To incorporate the material as a solid state electrolyte in a lithium ion battery a dense sintered ceramic is needed. Furthermore, a good electronic and ionic conduction in the electrodes has to be guaranteed. ${ }^{24}$ For the ionic conductivity a pure phase electrolyte powder with a high surface area is required. To ensure a good contact between electrodes and electrolyte in addition with a good mechanical stability the interest in hybrid electrolytes containing a solid state electrolyte and a polymer increases. ${ }^{25}$

In this work $\mathrm{Li}_{6.4} \mathrm{Fe}_{0.2} \mathrm{La}_{3} \mathrm{Zr}_{2} \mathrm{O}_{12}$ was synthesized via the solid state method and the sol gel method to investigate the phase purity after calcination. Further the sintering behavior, microstructure and phase

${ }^{\text {z} E-m a i l: ~ a n j . p a u l u s @ f z-j u e l i c h . d e ~}$ purity of sintered pellets was investigated by dilatometry, scanning electron microscopy (SEM) and X-Ray diffraction (XRD) with regard to the differences in the synthesis methods. The pellets where further characterized electrochemically to obtain information about total, bulk and grain boundary lithium ion conductivities measured by electrical impedance spectroscopy (EIS) and electrical conductivity measured by voltage step chronoamperometry.

\section{Experimental Part}

Solid state synthesis.-To synthesize $\mathrm{Li}_{6.4} \mathrm{Fe}_{0.2} \mathrm{La}_{3} \mathrm{Zr}_{2} \mathrm{O}_{12}$ via a solid state route stoichiometric amounts of $\mathrm{Fe}_{2} \mathrm{O}_{3} \mathrm{~m}=0.951 \mathrm{~g}$ (5.95 mmol, Sigma Aldrich, $\geq 99 \%) \mathrm{ZrO}_{2} \mathrm{~m}=14.67 \mathrm{~g} \mathrm{(119.1} \mathrm{mmol,}$ Sigma Aldrich, 99.5\% metals basis excluding Hf (Hf $<100 \mathrm{ppm})$ ) and $\mathrm{La}_{2} \mathrm{O}_{3} \mathrm{~m}=29.10 \mathrm{~g}$ (89.31 mmol, Alfa Aesar, 99.99\%, Ca 10 ppm max., dried at $700^{\circ} \mathrm{C}$ for $11 \mathrm{~h}$ and weighed in in a glove box) and $\mathrm{Li}_{2} \mathrm{CO}_{3} \mathrm{~m}=15.49 \mathrm{~g}$ (209.6 mmol, Sigma Aldrich, $\left.\geq 99 \%\right)$ with an excess of $10 \mathrm{~mol} \%$ were used. In a polyamide milling container YSZ-balls with diameters of $\emptyset_{1}=10 \mathrm{~mm}$ and $\emptyset_{2}=3 \mathrm{~mm}$ with a mass of $85 \mathrm{~g}$ each and the starting materials were mixed with $60 \mathrm{~mL}$ propan-2-ol and the container was closed. In the planetary ball mill PULVERISETTE 5 from Fritsch (Markt Einersheim, Germany) the suspension was milled for $4 \mathrm{~h}$ with a rotating speed of $250 \mathrm{rpm}$. The balls were taken out with a sieve while the suspension was collected in a flask. The solvent was removed in a rotational evaporator and the starting material mixture was calcined for $12 \mathrm{~h}$ in $\mathrm{Al}_{2} \mathrm{O}_{3}$ crucibles at a temperature of $950^{\circ} \mathrm{C}$. This temperature treatment does not lead to a cubic stabilization caused by aluminum contamination of the crucibles as shown in the supplement. To produce ceramics the calcined products $0.7 \mathrm{~g}$ were pressed with a $10 \mathrm{~mm}$ die in the uniaxial press (P-O-Weber, Remshalden, Germany) with a force of $10 \mathrm{kN}$ for $5 \mathrm{~min}$. Afterwards the pellets were further pressed for $30 \mathrm{~s}$ with a force of $1425 \mathrm{kN}$ in the cold isostatic press KIP-E 200 (P-O-Weber, Remshalden, Germany). The pellets where then sintered on a platinum mesh positioned in an $\mathrm{Al}_{2} \mathrm{O}_{3}$ crucible in a furnace for $2 \mathrm{~h}$ to avoid aluminum contamination from the crucibles. A temperature of $1225^{\circ} \mathrm{C}$ with heating and cooling rates of $5 \mathrm{~K} / \mathrm{min}$ were used. The influence of the sintering time was investigated by increasing the dwell from $2 \mathrm{~h}$ to $16 \mathrm{~h}$ for $\mathrm{Li}_{6.4} \mathrm{Fe}_{0.2} \mathrm{La}_{3} \mathrm{Zr}_{2} \mathrm{O}_{12}$ at temperatures of $1100^{\circ} \mathrm{C}$ and $1200^{\circ} \mathrm{C}$. 
To prevent a reaction with the ambient humidity, the calcined powders and sintered pellets were transferred into a glove box at temperatures above $200^{\circ} \mathrm{C}$ at the end of the furnace treatments and stored under Argon. ${ }^{26,27}$

Sol gel synthesis.-For the sol gel synthesis all starting materials where stored and weighed in in a glove box, as they are hygroscopic. To synthesize $\mathrm{Li}_{6.4} \mathrm{Fe}_{0.2} \mathrm{La}_{3} \mathrm{Zr}_{2} \mathrm{O}_{12}$ stoichiometric amounts of $\mathrm{Fe}\left(\mathrm{NO}_{3}\right)_{3}$. $9 \mathrm{H}_{2} \mathrm{O} \mathrm{m}=0.95 \mathrm{~g}(2.4 \mathrm{mmol}$, Sigma Aldrich, $\geq 99.95 \%$ trace metals basis), $\mathrm{La}\left(\mathrm{NO}_{3}\right)_{3} \cdot 6 \mathrm{H}_{2} \mathrm{O} \mathrm{m}=15.34 \mathrm{~g}$ (35.43 mmol, Alfa Aesar, $99.99 \%)$ and $\mathrm{LiNO}_{3} \mathrm{~m}=5.73 \mathrm{~g}(83.1 \mathrm{mmol}$, Sigma Aldrich, $\geq 99.0 \%)$ with an excess of $10 \mathrm{~mol} \%$ to compensate for Li-loss during high temperature treatment were dissolved in deionized $\mathrm{H}_{2} \mathrm{O}$ and stirred with a mechanical stirrer. A solution of the stoichiometric amounts of $\mathrm{ZrO}\left(\mathrm{NO}_{3}\right)_{2} \cdot \mathrm{x} \mathrm{H}_{2} \mathrm{O} \mathrm{m}=6.18 \mathrm{~g}$ (23.6 mmol, Alfa Aesar, 99.9\%) (with $\mathrm{x}=1.686$ determined gravimetric and by ICP-OES) in water was added and subsequently, an aqueous solution of citric acid $\left(\mathrm{C}_{6} \mathrm{H}_{8} \mathrm{O}_{7}\right.$. $1 \mathrm{H}_{2} \mathrm{O} \mathrm{m}=57.6 \mathrm{~g}(274 \mathrm{mmol}$, Sigma Aldrich, $\geq 99.5 \%)$ with an amount equivalent to twice the total moles of the metal cations was added. The mixture was stirred overnight at $40^{\circ} \mathrm{C}$ and subsequently heated to $120^{\circ} \mathrm{C}$ for gelation. The gel was dried at $250^{\circ} \mathrm{C}$ overnight. The dark brown product was ground and calcined in $\mathrm{Al}_{2} \mathrm{O}_{3}$ crucibles in a muffle furnace from Nabertherm $\mathrm{GmbH}$ (Lilienthal, Deutschland). The heating and cooling rate was set to $5 \mathrm{~K} / \mathrm{min}$ and a dwell of $2 \mathrm{~h}$ at $500^{\circ} \mathrm{C}$ was applied to decompose remaining organics and nitrates. The furnace treatment was finished with an optimized subsequent heating to $950^{\circ} \mathrm{C}$ for $12 \mathrm{~h}$ to form the calcined products. In the supplement the variation of time and temperature of the subsequent heating step is shown. To produce ceramics the calcined products were pressed analogue to the ones from the solid state route described before. The pellets where then sintered on a platinum mesh positioned in an $\mathrm{Al}_{2} \mathrm{O}_{3}$ crucible in a furnace at $1225^{\circ} \mathrm{C}$ for $2 \mathrm{~h}$ with heating and cooling rates of $5 \mathrm{~K} / \mathrm{min}$.

$\boldsymbol{X}$-Ray diffraction (XRD).- XRD was performed using an Empyrean from PANalytical (Almelo, Netherlands). The measurements were done in Bragg-Brentano geometry using $\mathrm{Ni}$ filtered $\mathrm{Cu}$ radiation with wavelengths of $\lambda_{\mathrm{K} \alpha 1}=1.540593 \AA$ and $\lambda_{\mathrm{K} \alpha 2}=$ $1.544412 \AA$ in a $2 \Theta$-range from $10^{\circ}$ to $80^{\circ}$. Detection was done with a linear Si-based X'Celerator from PANalytical (Almelo, Netherlands). Powders were measured in Argon atmosphere with a sample holder with polymer dome from PANalytical (Almelo, Netherlands) for the calcined sol gel powders. Pellets and solid state powders were measured in air.

Dilatometry.-The sintering behavior of the garnets was investigated using a DIL $402 \mathrm{C}$ dilatometer from Netzsch (Selb, Germany). The dilatometer was equipped with an $\mathrm{Al}_{2} \mathrm{O}_{3}$ sample holder and push rod and a $\mathrm{SiC}$ furnace. Before every measurement a correction with a $10 \mathrm{~mm}$ long polycrystalline $\mathrm{Al}_{2} \mathrm{O}_{3}$ standard with a diameter of $6 \mathrm{~mm}$ and the same temperature program was performed. To extract the pure sample length changes from the measurements these were corrected with the standard measurements and the software Proteus Analysis from Netzsch (Selb, Germany). All measurements were done under static air. Therefore, the calcined powders were pestled than pressed with an uniaxial press (P-O-Weber, Remshalden, Germany) to a size of $5 \cdot 5 \cdot 15 \mathrm{~mm}$ with a pressure of $10 \mathrm{kN}$ for $5 \mathrm{~min}$. Afterwards the pellets were pressed for $30 \mathrm{~s}$ with a force of $1425 \mathrm{kN}$ in the cold isostatic press KIP-E 200 (P-O-Weber, Remshalden, Germany). After pressing the Volume $V$ was measured with the caliper IP67 (Garant, Munich, Germany) and the pellets masses $m$ where weighed.

Scanning electron microscopy (SEM).-SEM images were taken on a Quanta FEG 650 from FEI (Hillsboro, Oregon, USA). The scans where done with an electron beam of $5 \mathrm{kV}$, a distance of $10 \mathrm{~mm}$ and a spot size of 4 in a vacuum of $p \leq 2 \cdot 10^{-6}$ mbar. The backscattered and secondary electrons were detected by a circular backscatter detector (CBS) and an Everhart-Thornley detector (ETD) respectively. The magnification of the images taken was between 100 to 10000 . Powder samples were suspended in an ultrasonic bath in anhydrous propan-2ol for 5 minutes. One droplet of the suspension was dispersed on an aluminum sample holder and dried in argon before taking images. For sintered pellets the surfaces were taken off with the preparation system Tegramin-25 (Struers, Ballerup, Denmark). The pellets were polished stepwise with different sized SiC-Paper used in the following order of FEPA values: 500, 800, 1200, 2000 two minutes each. In every step water free preparation oil was used and it was polished with a rotation speed of $80 \mathrm{rpm}$. For the fine-polishing procedure the polishing cloth MD DAK (Struers, Ballerup, Denmark) and the diamond suspension with particles of $3 \mu \mathrm{m}$ followed by the cloth MD NAD (Struers, Ballerup, Denmark) and the diamond suspension with particles of $1 \mu \mathrm{m}$ was used. After each fine-polishing step the pellet was cleaned with lapping oil and after the last step ultrasonic cleaned in anhydrous propan-2-ol for $9 \mathrm{~min}$. The samples were always stored in Argon atmosphere to avoid reactions with humidity.

Electrochemical characterization.-For the electrochemical characterization the pellets where polished down with SiC-Paper with a FEPA value of 500 to a thickness of $1.54 \mathrm{~mm}$. For the characterizations Platinum with a thickness of $400 \mathrm{~nm}$ was deposited on both sides of the pellets with the SPECTROS from Lesker. Electrochemical measurements were performed in the cell EQ-PSC from MTI Corporation on the potentiostat VSP-300 from Bio-Logic. For the EIS measurements a frequency range from $7 \mathrm{MHz}$ to $0.5 \mathrm{~Hz}$ in a temperature range from $5^{\circ} \mathrm{C}$ to $30^{\circ} \mathrm{C}$ was used. Between the measurements an OCV of $2 \mathrm{~h}$ was applied to reach the set temperature. The cells were measured in a climate chamber KB115 from Binder. For the electrical conductivity measurements constant DC Voltages between $0.1 \mathrm{~V}$ and $2 \mathrm{~V}$ where applied for $30 \mathrm{~min}$ each at $30^{\circ} \mathrm{C}$ and the resulting current was detected. Between each measurement an EIS between $1 \mathrm{MHz}$ and $0.1 \mathrm{kHz}$ was performed to make sure, that the measurement does not change the cell resistance.

\section{Results and Discussion}

Properties of the powder after calcination.-Fig. 1 shows the XRD pattern of the two calcined products synthesized via the solid state method and the sol gel method. Both samples exhibit the cubic garnet related structure in $I \overline{4} 3 d$ which can be seen by comparing the theoretical reflexes published by Wagner Et al. shown at the bottom of the left part of the figure with the measured diffractograms. ${ }^{15}$ Each theoretical reflex is split into two reflexes in the measurement, as two wavelengths were used (see exp. part). The powder obtained via the solid state method shows a combination of reflexes (Figure 1 right side) of the tetragonal and the cubic structure. Reflexes which can solely be found in the tetragonal structure at angles of $2 \Theta=27.1^{\circ}, 28.1^{\circ}, 31.3^{\circ}$ occur as well as those solely found in the cubic structure here shown at angles $2 \Theta=27.5^{\circ}, 30.8^{\circ}$. This means that the cubic structure is just partially stabilized by iron. The just partial cubic stabilization results from an inhomogeneous iron-distribution in the powders caused by mass transport limitations. In principle an iron content of $x=0.2$ in $\mathrm{Li}_{7-3 \mathrm{x}} \mathrm{Fe}_{\mathrm{x}} \mathrm{La}_{3} \mathrm{Zr}_{2} \mathrm{O}_{12}$ is sufficient to stabilize the cubic structure shown in literature. ${ }^{28}$ Thus, it is a mixture of the cubic garnet related phase and the tetragonal phase. The sol gel product is pure phase cubic structured. Due to the enhanced mixture of the metals on an atomic scale compared to a solid state method, reaction time or temperature or both can be significantly reduced as the mass transport limitation is lowered. ${ }^{29}$ Therefore, by using the same calcination conditions for both synthesis methods the powder obtained by the sol gel method shows a homogeneous iron distribution in the sample and that is why the cubic structure is present throughout the whole material. If one lowers the calcination temperature or shortens the calcination time for the sol gel synthesis a mixture of tetragonal and cubic phases is obtained as shown in the supplement. The large background found for the sol gel powder measurement especially visible for the angle range of $10^{\circ} \leq 2 \Theta \leq 30^{\circ}$ results from the "domed" sample holder. This sample holder was chosen, as the amount of product after a sol 

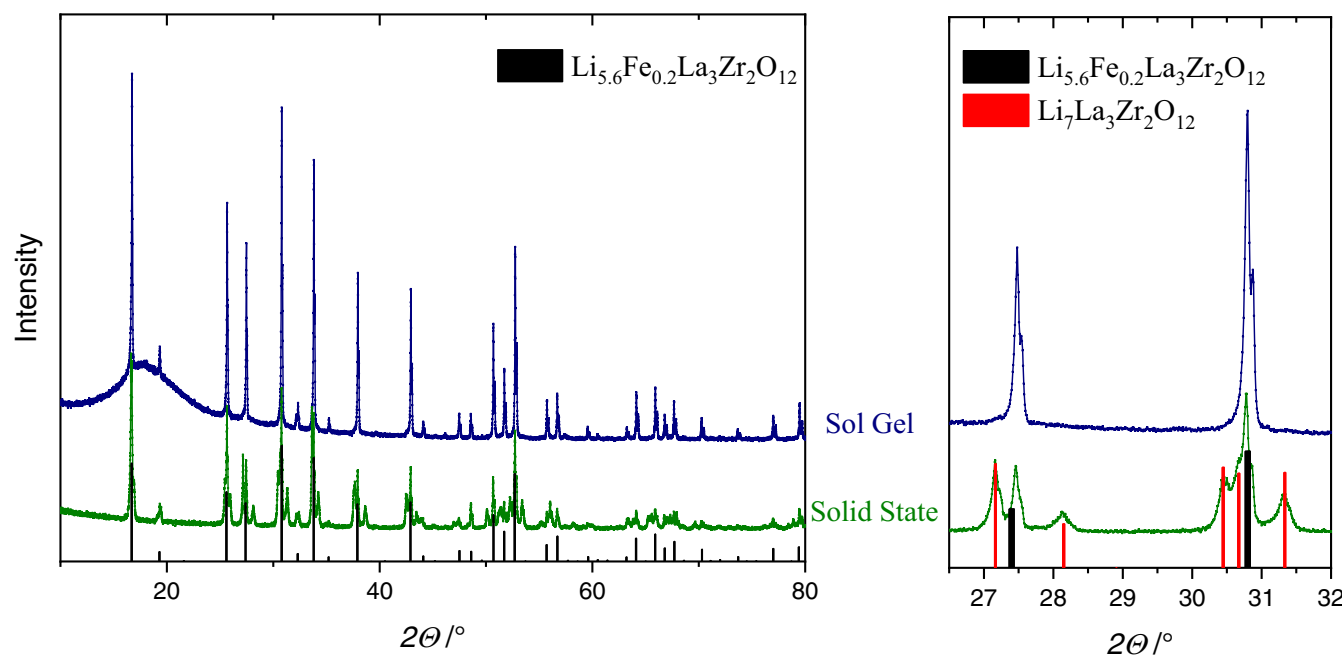

Figure 1. XRD pattern of calcined powders at $950^{\circ} \mathrm{C}$ for $12 \mathrm{~h}$ for the sol gel synthesis in dark blue and for the solid state synthesis in green. Reflex positions of the cubic phase with a 0 -offset of $0.6^{\circ}$ are shown in black and of the tetragonal phase in red at the bottom of the graphs..$^{15,36}$

gel synthesis is much lower than for the solid state synthesis and was therefore further used after the measurement and needed to be kept away from humidity.

In Fig. 2 SEM images of the calcined powders for the sol gel and solid state method are shown. Both samples contain similar microstructural features. For both materials sintered areas and branches can be observed. The sintered areas of the solid state powder exhibit sizes up to $50 \mu \mathrm{m}$ and branches with sizes ranging from 5-10 $\mu \mathrm{m}$. The sol gel powder exhibits sintered areas up to $30 \mu \mathrm{m}$ and branches around $5 \mu \mathrm{m}$ building up a coral like structure which can be seen in a magnification of 1000 in the left corner at the top. Furthermore, in the sol gel powder grains which are in good contact to each other with distinct grain boundaries are visible in the image with a magnification of 5000. These grains range from $1 \mu \mathrm{m}$ to $10 \mu \mathrm{m}$. The grain boundaries are mainly strong curved. A curved grain boundary compared to a straight one is energetically unfavored as grain boundaries contain a large amount of defects and the shortest distance is preferred. As the main driving force of a sintering process is the reduction of the free energy this curved boundaries show a strong tendency to further grow. $^{30}$

Sintering of $\mathrm{Li}_{6.4} \mathrm{Fe}_{0.2} \mathrm{La}_{3} \mathrm{Zr}_{2} \mathrm{O}_{12 .}$ - By in situ dilatometer measurements the densification process can be comprehended for the first
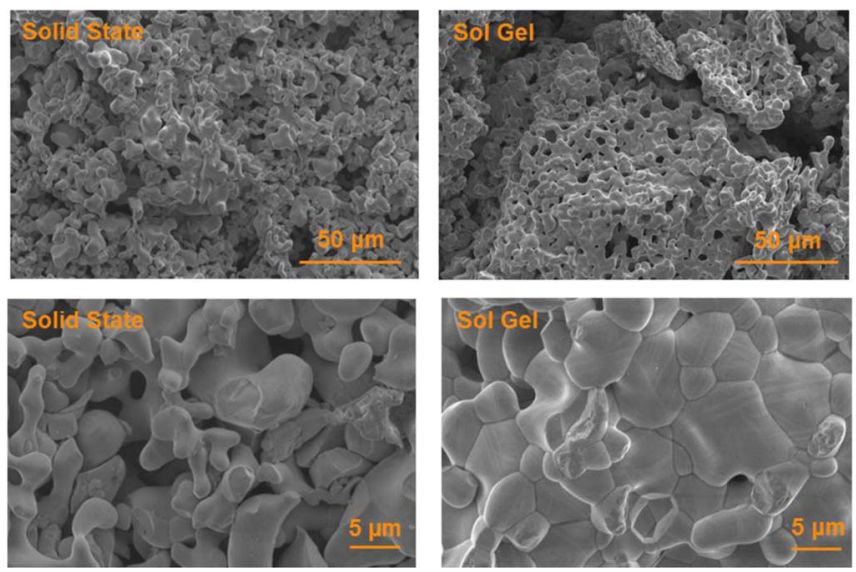

Figure 2. SEM images of $\mathrm{Li}_{6.4} \mathrm{Fe}_{0.2} \mathrm{La}_{3} \mathrm{Zr}_{2} \mathrm{O}_{12}$ powders calcined at $950^{\circ} \mathrm{C}$ for $12 \mathrm{~h}$ for the sol gel synthesis on the right and for the solid state synthesis on the left detected with an ETD detector. time for garnet materials shown in Fig. 3. The relative length of the pellets increases during heating for both samples until a temperature of $900^{\circ} \mathrm{C}$ is reached. The linear increase upon heating is expected for thermal expansion of a non-reacting ceramic. The sample synthesized via the solid state route, hereafter called the solid state pellet, shows an additional increase of the relative length between $500^{\circ} \mathrm{C} \leq T \leq$ $650^{\circ} \mathrm{C}$. The larger expansion between $500^{\circ} \mathrm{C} \leq \mathrm{T} \leq 650^{\circ} \mathrm{C}$ may be caused by the phase transition from the tetragonal to cubic structure. It was found, that the calcined powder contains an inhomogeneous irondistribution after calcination as shown by XRD before. This leads to an insufficient cubic stabilization of the powder and the presence of a tetragonal structured proportion in the green bodies. This interpretation fits to the phase transition temperature of $650^{\circ} \mathrm{C}$ reported in literature for unsubstituted $\mathrm{Li}_{7} \mathrm{La}_{3} \mathrm{Zr}_{2} \mathrm{O}_{12} .{ }^{31}$ The onset for the phase transition could be shifted to a slightly lower temperature as small amounts of iron could be present. At a temperature of $900^{\circ} \mathrm{C}$ the sintering process begins for both synthesis methods, and the pellets start to shrink, which can be seen in the decrease of the relative length. Further it is observable, that the sintering process stops after about a dwell of $2 \mathrm{~h}$ (marked with red lines) as the slope of the curve gets close to zero for the solid state pellet. For the product of the sol gel method,

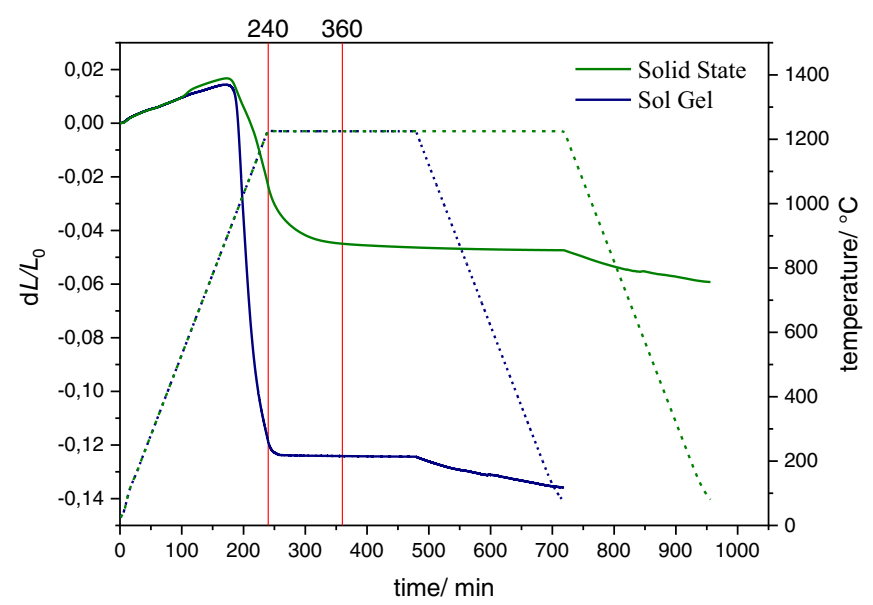

Figure 3. Dilatometer measurements of $\mathrm{Li}_{6.4} \mathrm{Fe}_{0.2} \mathrm{La}_{3} \mathrm{Zr}_{2} \mathrm{O}_{12}$ pellets synthesized by the sol gel method in dark blue and by the solid state method in green. The pellets were sintered at $1225^{\circ} \mathrm{C}$ with the temperature profile shown in the dashed lines. The red lines indicating the beginning and end of the densification process during dwell for the solid state route. 

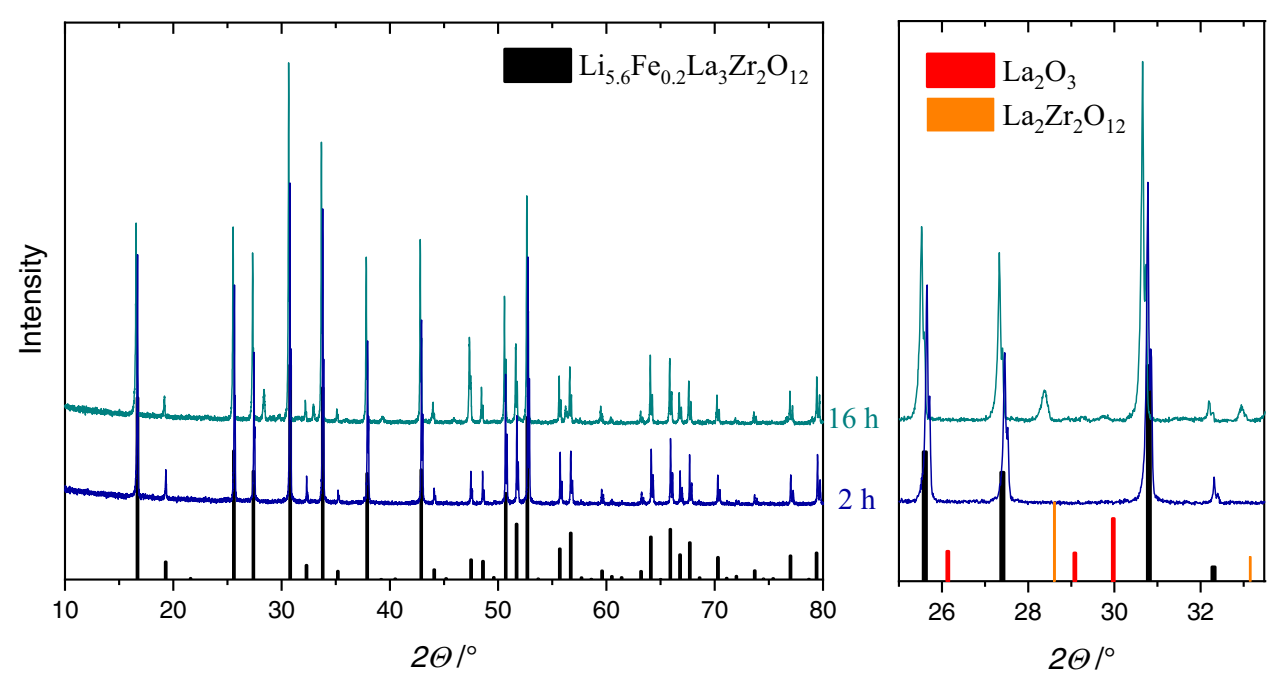

Figure 4. $\mathrm{XRD}$ of $\mathrm{Li}_{6.4} \mathrm{Fe}_{0.2} \mathrm{La}_{3} \mathrm{Zr}_{2} \mathrm{O}_{12}$ sintered at $1100^{\circ} \mathrm{C}$ for $2 \mathrm{~h}$ in blue and $16 \mathrm{~h}$ in cyan dark synthesized via the solid state route. On the left the full measuring range from $10^{\circ} \leq 2 \Theta \leq 80^{\circ}$ is shown together with the theoretical reflex positions of $\mathrm{Li}_{5.6} \mathrm{Fe}_{0.2} \mathrm{La}_{3} \mathrm{Zr}_{2} \mathrm{O}_{12}$ with a 0 -offset of $0.6^{\circ} .{ }^{15}$ On the right the $2 \Theta$-range from $25^{\circ}$ to $33^{\circ}$ is shown together with the theoretical reflex positions of $\mathrm{La}_{2} \mathrm{O}_{3}{ }^{37}$ and $\mathrm{La}_{2} \mathrm{Zr}_{2} \mathrm{O}_{7} .{ }^{38}$

hereafter called the sol gel pellet, the negative slope during shrinkage is much higher and gets zero after a dwell of $20 \mathrm{~min}$. Therefore, the sol gel pellet shows a much higher densification than the solid state pellet. Even though the dwell gets longer there is no further change in the relative length observable for both synthesis methods when the slope after densification gets close to zero, which means, that the density does not increase anymore. For longer dwells than $2 \mathrm{~h}$ for the solid state and $20 \mathrm{~min}$ for the sol gel pellet no benefit in terms of higher density is expected. This is significant shorter than the dwell times of $6 \mathrm{~h}$ at $1230^{\circ} \mathrm{C}$ or $16 \mathrm{~h}$ at $1050^{\circ} \mathrm{C}$ found in literature..$^{15,28}$ Upon cooling from $1225^{\circ} \mathrm{C}$ to room temperature an almost linear decrease is observable for both samples. This is caused by thermal contraction. From the green body densities and the relative length change after sintering and cooling down to room temperature densities can be calculated according to Equations 1 and 2. To calculate the geometrical green body density $\rho_{0}$ the following equation was used:

$$
\rho_{0}=\frac{m}{V}
$$

To calculate densities after a dilatometer measurement Equation 2 was applied.

$$
\rho=\frac{\rho_{0}}{\left(1+d L / L_{0}\right)^{3}}
$$

$d L / L_{0}$ was received from the dilatometer measurements after cooling down to room temperature. To calculate the relative density $\rho_{\text {rel }}$ the following equation was used:

$$
\rho_{\text {rel }}=\frac{\rho}{\rho_{\text {theo }}} \cdot 100 \%
$$

With $\rho_{\text {theo }}$ being $5.076 \mathrm{~g} / \mathrm{cm}^{3} .{ }^{15}$

The density can be significantly increased by the usage of the sol gel synthesis compared to the solid state synthesis as can be seen in Table I.

Table I. Densities for the pellets of the sol gel and the solid state method before and after sintering at $1225^{\circ} \mathrm{C}$.

Solid State Sol Gel

$\begin{array}{ccc}\rho_{0} / \mathrm{g} \cdot \mathrm{cm}^{-3} & 3.62 & 3.15 \\ \rho / \mathrm{g} \cdot \mathrm{cm}^{-3} & 4.35 & 4.88 \\ \rho_{\text {rel }} / \% & 85.7 & 96.1\end{array}$

Influence of the sintering time.- $\mathrm{XRD}$ of the pellet surfaces synthesized via solid state method sintered for $2 \mathrm{~h}$ and $16 \mathrm{~h}$ at $1100^{\circ} \mathrm{C}$ was performed as shown in Fig. 4 to study the structure and phase purity. Both diffractograms show the desired cubic garnet related structure in $I \overline{4} 3 \mathrm{~d}$. The sample sintered for $16 \mathrm{~h}$ at $1100^{\circ} \mathrm{C}$ shows some additional reflexes which can be attributed to the secondary phases of $\mathrm{La}_{2} \mathrm{O}_{3}$ and $\mathrm{La}_{2} \mathrm{Zr}_{2} \mathrm{O}_{7}$ as can be seen in the right figure. This is caused by lithium loss due to the high temperature treatment. Hence, lithium poor secondary phases such as $\mathrm{La}_{2} \mathrm{O}_{3}$ and $\mathrm{La}_{2} \mathrm{Zr}_{2} \mathrm{O}_{7}$ are formed caused by the decomposition of the material. The sample sintered for $2 \mathrm{~h}$ at $1100^{\circ} \mathrm{C}$ is pure phase cubic structured. This shows, that by reducing the sintering time the lithium loss caused by the high temperature treatment can be reduced.

The comparison of the influence of the sintering time at a higher temperature of $1200^{\circ} \mathrm{C}$ revealed an additional information as can be seen in the SEM images in Fig. 5. The SEM image with a magnification of 100 of the sample sintered at $1200^{\circ} \mathrm{C}$ for $2 \mathrm{~h}$ on the left picture shows a stable pellet without cracks. On the right side the SEM image of the pellet sintered at $1200^{\circ} \mathrm{C}$ for $16 \mathrm{~h}$ is shown. On the one hand, large cracks are observable which are distributed over the whole pellet surface. On the other hand, the pellet shows a color contrast with mostly dark gray areas and some pale gray areas which formed along cracks. As mentioned before during high temperature treatment for long dwells a Li loss at pellet surfaces occurs. This leads to secondary phases such as $\mathrm{La}_{2} \mathrm{O}_{3}$ and $\mathrm{La}_{2} \mathrm{Zr}_{2} \mathrm{O}_{7}$ shown by XRD. Both secondary phases have higher electron densities than $\mathrm{Li}_{6.4} \mathrm{Fe}_{0.2} \mathrm{La}_{3} \mathrm{Zr}_{2} \mathrm{O}_{12}$ and appear accordingly, in a lighter color in the SEM image. The secondary phases are mainly present along cracks where also the highest porosity occurs. This may confirm, that the cracks form due to material
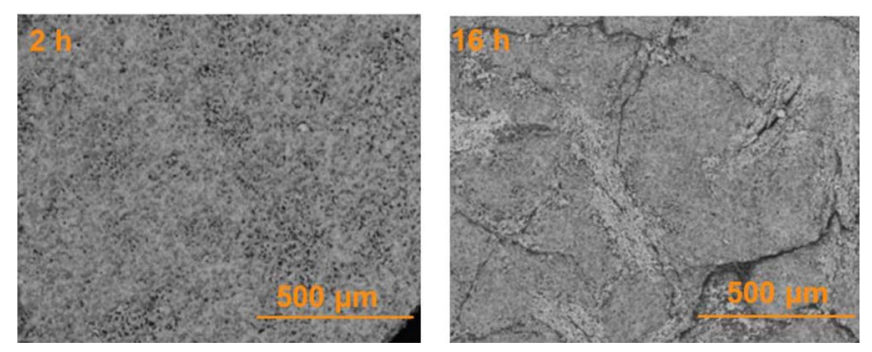

Figure 5. SEM images of $\mathrm{Li}_{6.4} \mathrm{Fe}_{0.2} \mathrm{La}_{3} \mathrm{Zr}_{2} \mathrm{O}_{12}$ pellets synthesized via the solid state method and sintered at $1200^{\circ} \mathrm{C}$ for $2 \mathrm{~h}$ on the left and $16 \mathrm{~h}$ on the right detected by a CBS detector. 


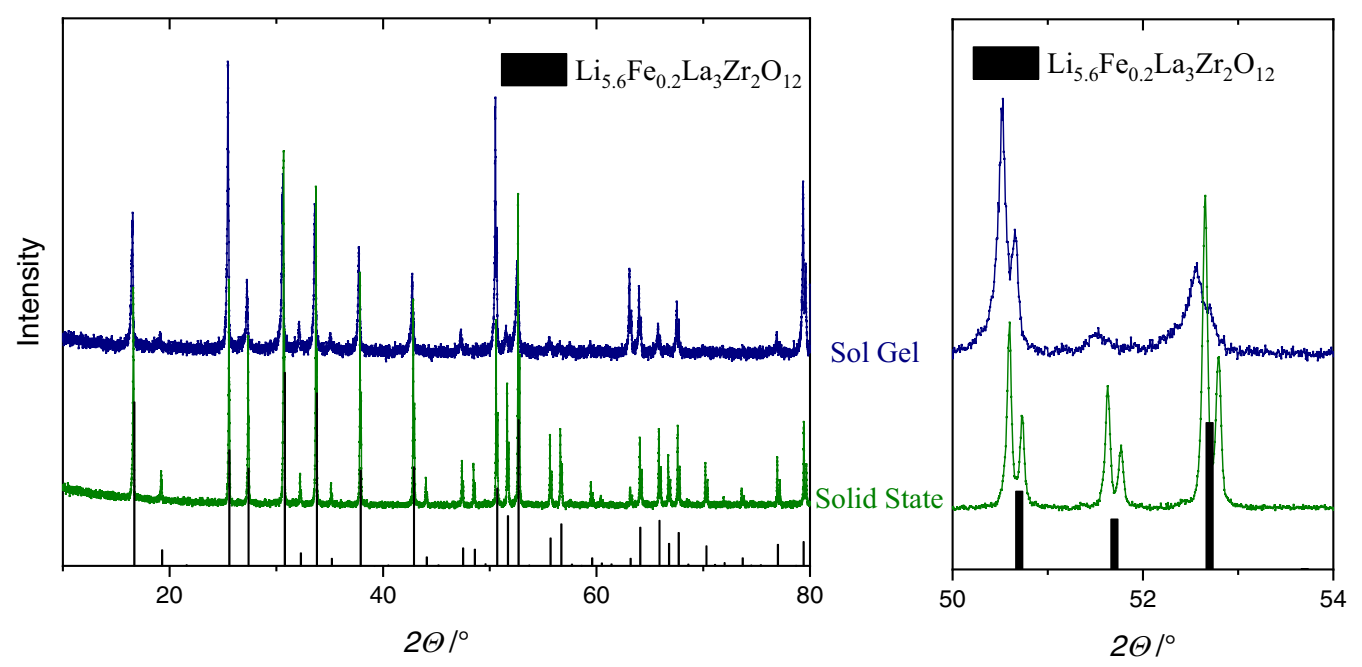

Figure 6. XRD pattern of pellets sintered at $1225^{\circ} \mathrm{C}$ for $2 \mathrm{~h}$ for the sol gel synthesis in dark blue and for the solid state synthesis in green. Reflex positions of the cubic phase with a 0 -offset of $0.6^{\circ}$ are shown in black. ${ }^{15}$

decomposition, where the evaporation of $\mathrm{Li}_{2} \mathrm{O}$ leads to high porosity and thus to an instability of the pellet. Therefore, pellet stability occurs as a function of time. Either the XRD or the SEM images with different sintering times confirm, that a lower sintering time is preferable as secondary phases due to lithium loss can be reduced and the pellet stability is enhanced which might lower the lithium ion conductivity.

Structural and microstructural properties of sintered pellets.In Fig. 6 XRD pattern for the comparison of the sol gel method vs the solid state method are shown. Both samples have the desired pure phase cubic structure. This also confirms, why no phase transition especially for the cooling of the solid state pellet during dilatometer measurements is found. The three depicted reflexes show different intensity ratios for the two samples. Furthermore, only the solid state pellet fits the reflex intensity ratios of the cubic structured $\mathrm{Li}_{5.6} \mathrm{Fe}_{0.2} \mathrm{La}_{3} \mathrm{Zr}_{2} \mathrm{O}_{12}$ from literature shown in in black bars at the bottom. ${ }^{15}$ Two main reasons can lead to such an observation. First a different site occupation may vary intensity ratios. As different lattice planes consist of different ratios of different atoms, they lead to different intensities in the diffraction pattern. If one now changes the site occupation with atoms of a different scattering length, reflex intensities sensitive to that crystallographic site vary. Usually a variation in site occupancy would show a variation in lattice constant. This would be especially good visible at higher angle as shown here. The reflexes do not show strong changes in lattice parameter, what hints to the fact, that similar occupations for the two samples are found. The second reason for changing intensity ratios maybe caused by a preferred orientation. In an ideal powder all possible lattice planes are hit randomly by the X-Rays leading to constant intensity ratios for each measurement. If the number of lattice planes found at the measured surface are decreased for example to one of a single crystal only one reflex will be observed. The larger the grain size in a sintered pellet surface the less powder like behavior is found in XRD measurements resulting in preferred orientation. Hence, these measurements indicate to a large grain size in the sintered pellets for the sol gel method and much smaller grain size in the pellet synthesized via the solid state route.

Fig. 7 shows SEM images for both synthesis routes. For the solid state pellet tubular shaped pores are found indicating an intermediate stage of sintering, while the pores are spherical shaped for the sol gel pellet indicating the final stage of sintering. ${ }^{32}$ For the solid state pellet a higher amount of pores with a larger size are found in comparison to the sol gel pellet which is in agreement with the lower density found by dilatometer measurements.
Lithium-ion conductivity.-The lithium ion conductivity derives from simulations of the Nyquist plots for both pellets of the different synthesis methods shown in Fig. 8. The lithium effective ionic conductivities $\sigma_{\text {ionic }}$ were calculated taking into account the pellet thickness $d$ and the sputtered Area $A$ for the resistances $R$ of the different semicircles:

$$
\sigma_{\text {ionic }}=\frac{d}{R \cdot A}
$$

The sol gel pellet shows only one semicircle with an almost linear increase at lower frequencies similar to the one found by Wagner et al. and thus a similar equivalent circuit model was used. ${ }^{15}$ The data can be described by only one resistor in parallel to a constant phase element as shown in Fig. 8 leaving out the Warburg short as this element contains mainly electrode information it will not be discussed further. For the solid state pellet two semicircles occur followed by an almost linear increase for lower frequencies. Therefore the equivalent circuit model was adjusted. As the sol gel pellets have a crystallite size in the order of the pellet thickness $d$ solely the bulk material contributes to the impedance and only one semicircle is observable (See SEM images in the supplementary). In contrast the solid state pellet has a crystallite size about an order of magnitude smaller, and thus a combination of bulk and grain boundaries contribute to the impedance as usual for a polycrystalline material. Furthermore the density of the solid state sample is lower. These facts lead to the differences observed in the
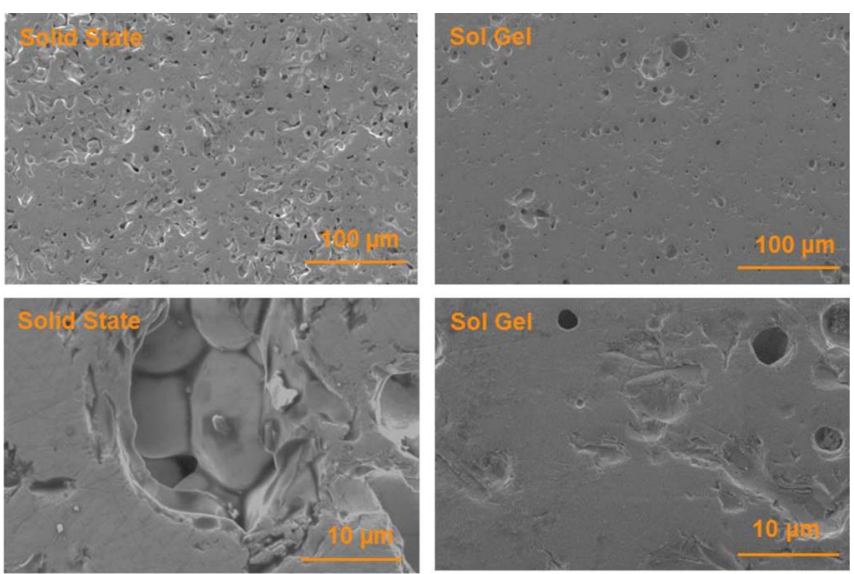

Figure 7. SEM images of $\mathrm{Li}_{6.4} \mathrm{Fe}_{0.2} \mathrm{La}_{3} \mathrm{Zr}_{2} \mathrm{O}_{12}$ pellets sintered at $1225^{\circ} \mathrm{C}$ for the sol gel synthesis on the right and for the solid state synthesis on the left detected with an ETD detector. 

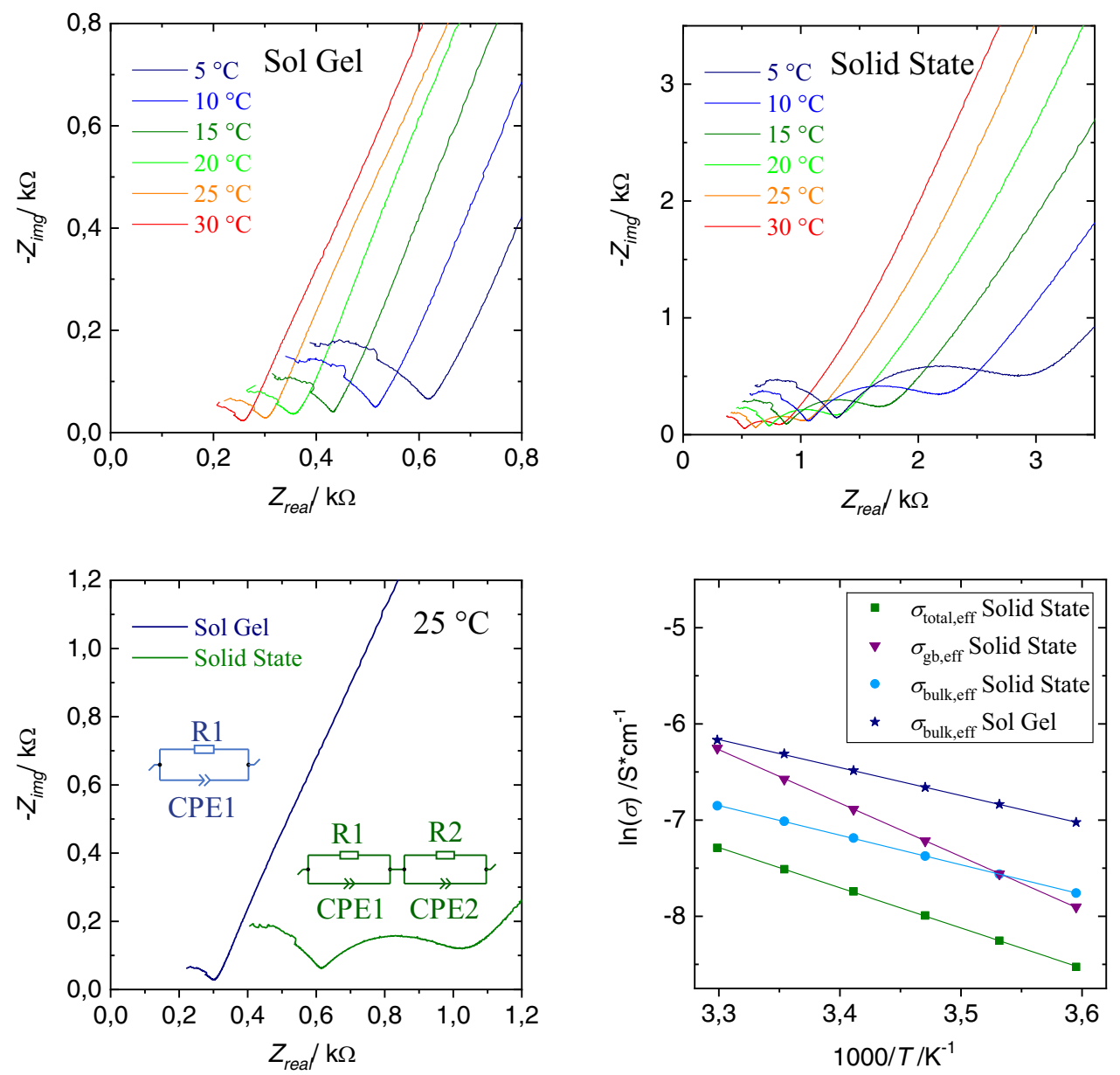

Figure 8. EIS of the sol gel pellet upper left and the solid state pellet upper right measured at different temperatures. The lower left figure shows the comparison of the EIS for both pellets at $25^{\circ} \mathrm{C}$. The lower right figure shows the Arrhenius plot of the different processes found for both pellets.

Nyquist plots hence the equivalent circuit models had to be adjusted. The resulting total $\sigma_{\text {ionic }}$ for the sol gel pellet is $1.82 \mathrm{mS} / \mathrm{cm}$ at $25^{\circ} \mathrm{C}$ which is the highest value measured so far for garnet related or garnet type materials. The total $\sigma_{\text {ionic }}$ for the solid state pellet is lower with $0.55 \mathrm{mS} / \mathrm{cm}$ which could be caused for the same reasons as mentioned above. From the fitted semicircles at different temperatures and the resulting Arrhenius plots, the activation energy can be determined as shown in Fig. 8 lower right. For the sol gel pellet the activation energy $E_{a}$ is at $0.25 \mathrm{eV}$ while the one for the solid state pellet is at $0.37 \mathrm{eV}$ split into $0.27 \mathrm{eV}$ for the first semicircle and $0.48 \mathrm{eV}$ for second one. By comparing the $E_{a}$ for the first semicircle of the solid state pellet and the semicircle found for the sol gel pellet one can say, that these are the same processes, as also the capacitance are within an order of $10 \mathrm{nF}$ for both synthesis methods. Therefore, this process can clearly be attributed to the bulk process. The second semicircle shows a much higher $E_{a}$ and a different capacitance within an order of $10 \mu \mathrm{F}$. Thus this process can be attributed to a grain boundary process. The proportion of the resistances from grain boundary to bulk at $25^{\circ} \mathrm{C}$ corresponds to $1: 1.55$. From the SEM images in the supplement it is obvious that the proportion of grain boundary to bulk material is significantly lower. Conversely, this means that the bulk conductivity must be higher than that of the grain boundaries. For an accurate determination of the specific conductivities, the exact proportions, geometry and arrangement of grains and grain boundaries would need to be considered. .3,34 $^{3,3}$

Electrical conductivity.-For the determination of the electrical conductivity the current values of each Voltage step where taken when reaching a steady state, assuming ohmic behavior like reported by
Aguesse et al. ${ }^{35}$ The results are shown in Fig. 9. The values of the electrical conductivity at $30^{\circ} \mathrm{C}$ are found to be $82 \mathrm{nS} / \mathrm{cm}$ for the solid state pellet and $111 \mathrm{nS} / \mathrm{cm}$ for the sol gel pellet. The electrical conductivity is higher for the sol gel pellet than found for the solid state pellet as density and microstructure differs. Nevertheless, as the crystallite size is about an order of magnitude larger in the sol gel pellets which means less defects caused by grain boundaries compared to the solid state pellet, the bulk material contributes to the electrical conductivity. For $\mathrm{Li}_{6.55} \mathrm{Ga}_{0.15} \mathrm{La}_{3} \mathrm{Zr}_{2} \mathrm{O}_{12}$ an electrical conductivity of

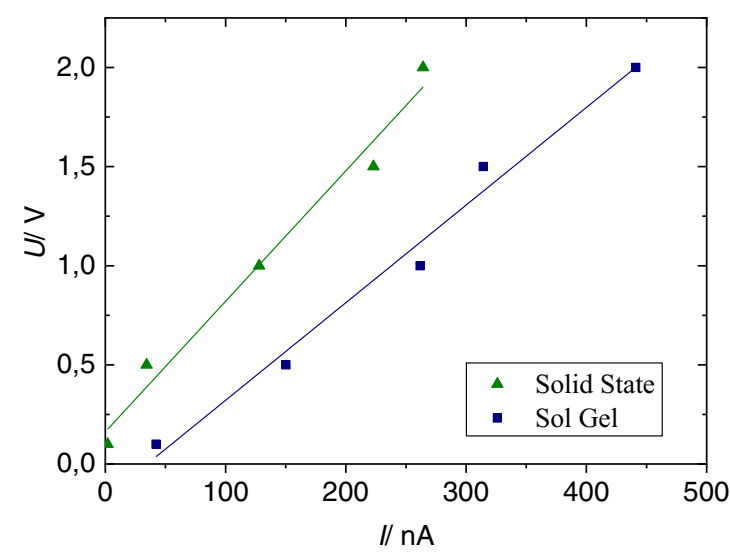

Figure 9. Results of the Voltage-step chronoamperometry for the sol gel pellet in blue and the solid state pellet in green along with the linear fit according to Ohm's law. 
$1 \mathrm{nS} / \mathrm{cm}$ was found at $25^{\circ} \mathrm{C} .{ }^{35}$ The higher electrical conductivity could be advantageous for the usage as powder on the electrode site, as in bulk type batteries the active material is usually mixed with the electrolyte material and carbon black to ensure ionic and electrical conductivity.

\section{Conclusions}

It was shown that by using the sol gel method compared to the solid state method the homogeneity can significantly been increased resulting in the desired pure phase cubic structured powders after calcination The solid state method leads to powders containing a mixture of cubic and tetragonal phases caused by mass transport limitations. By dilatometer measurements we were able to show, that the densification process stops after $2 \mathrm{~h}$ for the solid state and $20 \mathrm{~min}$ for the sol gel pellets at $1225^{\circ} \mathrm{C}$ resulting in densities of $86 \%$ and $96 \%$ respectively. By reducing the sintering time secondary phases can be avoided and the pellet stability is enhanced resulting in pure phase cubic structured pellets for both synthesis methods. Sintered pellets of $\mathrm{Li}_{6.4} \mathrm{Fe}_{0.2} \mathrm{La}_{3} \mathrm{Zr}_{2} \mathrm{O}_{12}$ show the fastest lithium-ion conduction measured so far for garnet-type or garnet-related materials with $1.82 \mathrm{mS} / \mathrm{cm}$ with an activation energy of $0.25 \mathrm{eV}$ for the sol gel pellets. For the sol gel pellets only the bulk contributes to the lithium-ion conduction as the crystallite size is in the order of the pellet thickness. The solid state pellet shows polycrystalline behavior with grain boundaries and bulk with a much smaller crystallite size. Further it was shown that the specific bulk ionic conductivity is higher than the one for the grain boundaries at $25^{\circ} \mathrm{C}$. For the usage as a solid state electrolyte a single crystal material should be preferred as it therefore would result in a higher total lithium ion conductivity. The electrical conductivity of $111 \mathrm{nS} / \mathrm{cm}$ was found for the sol gel pellet and $82 \mathrm{nS} / \mathrm{cm}$ for the solid state pellet. Thus this material is either interesting for the usage in an hybrid electrolyte or as powder on the electrode sites. In this work we have shown that with a selective synthesis of a specific morphology, the relationship between bulk, grain boundary and total ionic conductivity can be determined.

\section{Acknowledgment}

The authors gratefully thank Achim Weber for depositing platinum onto the pellets and Izaak C. Vinke for discussions on the impedance data and Deniz Guenduez for showing the SEM pellet preparation procedure.

\section{ORCID}

Anja Paulus (1) https://orcid.org/0000-0001-7441-6920

\section{References}

1. J. B. Goodenough and K.-S. Park, Journal of the American Chemical Society, 135(4), 1167 (2013).
2. A. Manthiram, X. Yu, and S. Wang, Nature Reviews Materials, 2, 16103 (2017).

3. A. C. Luntz, J. Voss, and K. Reuter, The Journal of Physical Chemistry Letters, $\mathbf{6}(22)$, 4599 (2015).

4. V. Thangadurai, S. Narayanan, and D. Pinzaru, Chem. Soc. Rev., 43, 4714 (2014).

5. J.-F. Wu, W. K. Pang, V. K. Peterson, L. Wei, and X. Guo, ACS Applied Materials \& Interfaces, (2017).

6. K. Fu, Y. Gong, B. Liu, Y. Zhu, S. Xu, Y. Yao, W. Luo, C. Wang, S. D. Lacey, J. Dai, Y. Chen, Y. Mo, E. Wachsman, and L. Hu, Science Advances, 3(4), (2017).

7. Y. Zhu, X. He, and Y. Mo, ACS Applied Materials \& Interfaces, 7(42), 23685 (2015)

8. R. Murugan, V. Thangadurai, and W. Weppner, Angew. Chem., Int. Ed., 46, 7778 (2007).

9. J. Awaka, N. Kijima, H. Hayakawa, and J. Akimoto, J. Solid State Chem., 182, 2046 (2009).

10. C. A. Geiger, E. Alekseev, B. Lazic, M. Fisch, T. Armbruster, R. Langner, M. Fechtelkord, N. Kim, T. Pettke, and W. Weppner, Inorg. Chem., 50, 1089 (2011).

11. Y. Chen, E. Rangasamy, C. Liang, and K. An, Chemistry of Materials, 27(16), 5491 (2015).

12. D. Rettenwander, G. Redhammer, F. Preishuber-Pflügl, L. Cheng, L. Miara, R. Wagner, A. Welzl, E. Suard, M. M. Doeff, M. Wilkening, J. Fleig, and G. Amthauer, Chemistry of Materials, 28(7), 2384 (2016).

13. D. Rettenwander, C. A. Geiger, and G. Amthauer, Inorganic Chemistry, 52(14), 8005 (2013).

14. L. J. Miara, W. D. Richards, Y. E. Wang, and G. Ceder, Chemistry of Materials, 27(11), 4040 (2015).

15. R. Wagner, G. J. Redhammer, D. Rettenwander, G. Tippelt, A. Welzl, S. Taibl, J. Fleig, A. Franz, W. Lottermoser, and G. Amthauer, Chemistry of Materials, (2016).

16. K. Ishiguro, Y. Nakata, M. Matsui, I. Uechi, Y. Takeda, O. Yamamoto, and N. Imanishi, Journal of The Electrochemical Society, 160(10), A1690 (2013).

17. Y. Wang and W. Lai, Electrochemical and Solid-State Letters, 15(5), A68 (2012).

18. A. Dumon, M. Huang, Y. Shen, and C.-W. Nan, Solid State Ionics, 243, 36 (2013).

19. J. Awaka, N. Kijima, H. Hayakawa, and J. Akimoto, Journal of Solid State Chemistry, 182(8), 2046 (2009).

20. R. Murugan, S. Ramakumar, and N. Janani, Electrochemistry Communications, 13(12), 1373 (2011)

21. V. Thangadurai and W. Weppner, Advanced Functional Materials, 15(1), 107 (2005).

22. V. Thangadurai and W. Weppner, Journal of the American Ceramic Society, 88(2), 411 (2005).

23. Y. Shimonishi, A. Toda, T. Zhang, A. Hirano, N. Imanishi, O. Yamamoto, and Y. Takeda, Solid State Ionics, 183(1), 48 (2011).

24. J. Janek and W. G. Zeier, Nature Energy, 1, 16141 (2016).

25. F. Langer, I. Bardenhagen, J. Glenneberg, and R. Kun, Solid State Ionics, 291, 8 (2016).

26. M. Nyman, T. M. Alam, S. K. McIntyre, G. C. Bleier, and D. Ingersoll, Chemistry of Materials, 22(19), 5401 (2010)

27. L. Truong and V. Thangadurai, Chemistry of Materials, 23(17), 3970 (2011).

28. D. Rettenwander, C. A. Geiger, M. Tribus, P. Tropper, R. Wagner, G. Tippelt, W. Lottermoser, and G. Amthauer, Journal of Solid State Chemistry, 230, 266 (2015).

29. M. Zayat and D. Levy, Chemistry of Materials, 12(9), 2763 (2000).

30. N. P. Bansal and A. R. Boccaccini, Ceramics and composites processing methods, Hoboken, N. J, Wiley (2012).

31. G. Larraz, A. Orera, and M. L. Sanjuan, Journal of Materials Chemistry A, 1(37), 11419 (2013).

32. R. M. German, Sintering: from empirical observations to scientific principles (2014).

33. P. G. Bruce, Journal of The Electrochemical Society, 130(3), 662 (1983).

34. A. Mertens, S. Yu, N. Schön, D. C. Gunduz, H. Tempel, R. Schierholz, F. Hausen, H. Kungl, J. Granwehr, and R.-A. Eichel, Solid State Ionics, 309, 180 (2017)

35. F. Aguesse, W. Manalastas, L. Buannic, Lopez del Amo, Juan Miguel, G. Singh, A. Llordes, and J. A. Kilner, ACS Applied Materials \& Interfaces, (2017).

36. A. Logéat, T. Köhler, U. Eisele, B. Stiaszny, A. Harzer, M. Tovar, A. Senyshyn, H. Ehrenberg, and B. Kozinsky, Solid State Ionics, 206, 33 (2012).

37. P. Aldebert and J. P. Traverse, Materials Research Bulletin, 14(3), 303 (1979)

38. P. E. R. Blanchard, R. Clements, B. J. Kennedy, C. D. Ling, E. Reynolds, M. Avdeev, A. P. J. Stampfl, Z. Zhang, and L.-Y. Jang, Inorganic Chemistry, 51(24), 13237 (2012). 